\title{
STRUCTURE OF THE ANALYTICAL ACTIVITY OF THE HEAD OF SCHOOL
}

(C) 2016

N.N. Koval, methodist

Donetsk Republican Institute of Additional Pedagogical Education, Donetsk (Donetsk People's Republic)

Abstract. The article deals with the current pedagogical approaches to the components, structure and description of analytical activity. Different models of analytical activity are reviewed: activity approach (E.V. Naznachilo, N.A. Zinchuk, V.V. Yagupov, N.P. Pichugova), systematic approach (L.P. Polovenko, O.N. Yarygin, and A.A. Korostelev), structuralactivity approach (L.M. Plakhova). Within each approach the main components and stages of the analytical activity are described. The emphasis is laid on the three-dimensional model of analytical practice of the school principal: the technology of the analysis of the results of educational system operation (A.A. Korostelev), the element of that is a heuristic algorithm of unmathematical character, consisting of five stages. This technology combined a motivational sense, target, technological levels. The structural components of the analytical activity of the school's head are highlighted and described: value-motivation (personality attitude of leader toward analytical activity, value of parties and her meaningfulness in administrative activity, necessity of personality to improve and develop in this type of activity), goal-oriented (intentional aspect), cognitive-operational (complex of knowledge, abilities, practical skills, necessary for realization of effective and effective analytical activity) and reflective (self-esteem, self-awareness, self-management, self-design their own analytical activities).

Keywords: analysis, practice, analytical practice, analytical practice of the principal, structure analysis program, the stages of analytical practice, activity approach, system approach.

\section{УДК 376.016: 51}

\section{ПОДГОТОВКА БУДУЩИХ УЧИТЕЛЕЙ К РАБОТЕ С ДЕТЬМИ, ИСПЫТЫВАЮЩИМИ ТРУДНОСТИ В ОСВОЕНИИ ОСНОВНЫХ ОБРАЗОВАТЕЛЬНЫХ ПРОГРАММ ОБЩЕГО ОБРАЗОВАНИЯ, РАЗВИТИИ И СОЦИАЛЬНОЙ АДАПТАЦИИ}

(C) 2016

И.К. Кондаурова, кандидат педагогических наук, доцент, заведующий кафедрой математики и методики ее преподавания Саратовский национальный исследовательский государственный университет, Саратов (Россия)

Аннотаџия. В статье предложен авторский подход к проектированию и реализации профессиональнометодической подготовки будущих учителей математики к работе с детьми, испытывающими трудности в освоении основных образовательных программ общего образования, развитии и социальной адаптации, в том числе с детьми с ограниченными возможностями здоровья, в контексте требований Национальной образовательной инициативы «Наша новая школа», Национальной стратегии действий в интересах детей на 2012-2017 годы, ряда других нормативных документов. Обозначены цели изучения, планируемые результаты и примерное содержание раздела «Методика обучения математике учащихся, испытывающих трудности в освоении основных образовательных программ общего образования, развитии и социальной адаптации, в том числе детей с ограниченными возможностями здоровья» дисциплины «Методика обучения математике детей с особыми образовательными потребностями». Структура содержания раздела представлена тремя модулями. Первый связан с изучением психологопедагогических аспектов и нормативно-документального обеспечения обучения, воспитания и развития учащихся, испытывающих трудности в освоении основных образовательных программ общего образования, развитии и социальной адаптации. Второй модуль включает в себя общие вопросы методики обучения математике учащихся, испытывающих трудности в освоении основных образовательных программ общего образования, развитии и социальной адаптации. В третьем модуле представлены частные вопросы методики обучения математике учащихся, испытывающих трудности в освоении основных образовательных программ общего образования, развитии и социальной адаптации. В заключение статьи приведены рекомендации по организации учебно-исследовательской деятельности будущих учителей математики в контексте изучаемого методического материала.

Ключевые слова: подготовка будущих учителей; дети, испытывающие трудности в освоении основных образовательных программ общего образования, развитии и социальной адаптации; дети с ограниченными возможностями здоровья.

Актуальность затронутой в статье темы обусловлена повышенным вниманием государства к детям с ограниченными возможностями здоровья, что нашло отражение в ряде нормативных документов: Национальной образовательной инициативе «Наша новая школа», Национальной стратегии действий в интересах детей на 2012-2017 годы, проекте Концепции Федерального государственного образовательного стандарта (ФГОС) для обучающихся с ограниченными возможностями здоровья (ОВ3).
В Национальной образовательной инициативе «Наша новая школа» (утверждена Президентом Российской Федерации 4 февраля 2010 года, Пр-271) сформулирован основной принцип инклюзивного образования: «Новая школа - это школа для всех. В любой школе будет обеспечиваться успешная социализация детей с ограниченными возможностями здоровья, детей-инвалидов, детей, оставшихся без попечения родителей, находящихся в трудной жизненной ситуации. ... В каждом образовательном учреждении должна быть 
создана универсальная безбарьерная среда, позволяющая обеспечить полноценную интеграцию детейинвалидов» [1]. Документом была предусмотрена разработка и принятие государственной программы «Доступная среда», направленной на разрешение этой проблемы.

Национальная стратегия действий в интересах детей на 2012-2017 годы (утверждена Указом Президента РФ 1 июня 2012 года № 761) признает социальную исключенность уязвимых категорий детей (дети-сироты и дети, оставшиеся без попечения родителей, дети-инвалиды и дети, находящиеся в социально опасном положении) и ставит задачи [2]:

- законодательного закрепления правовых механизмов реализации права детей-инвалидов и детей с OB3 на включение в существующую образовательную среду на уровне дошкольного, общего и профессионального образования (права на инклюзивное образование);

- обеспечения предоставления детям качественной психологической и коррекционно-педагогической помощи в образовательных учреждениях;

- внедрения эффективного механизма борьбы с дискриминацией в сфере образования для детейинвалидов и детей с ОВ3 в случае нарушения их права на инклюзивное образование.

Одной из основных мер государственной поддержки детей-инвалидов и детей с ОВ3 в Национальной стратегии [2] обозначена организация системы подготовки специалистов для работы с детьми-инвалидами и детьми с ОВ3 на базе образовательных организаций высшего образования с использованием их богатого научно-практического потенциала.

Несомненно, для того чтобы каждый проблемный ребенок в процессе обучения математике получил тот вид и объем педагогической помощи, в котором он нуждается, необходима специальная подготовка педагогических кадров $[3,4]$. Во-первых, владеющих междисциплинарными знаниями о психолого-педагогических и организационных особенностях процессов обучения, воспитания и развития обучающихся с ОВ3, особенностях реализации инклюзивного (интегрированного) образования [5-12]; о трудностях в обучении математике, которые возникают у детей с ОВ3 под влиянием внутренних и внешних факторов на различных этапах взросления, во-вторых, способных с опорой на современные педагогические методики осуществлять своевременную диагностику, профилактику и коррекцию математического развития учащихся. Центральным звеном такой подготовки в ФГБОУ ВО «Саратовский национальный исследовательский государственный университет имени Н.Г. Чернышевского» является раздел дисциплины «Методика обучения математике детей с особыми образовательными потребностями», посвященный обучению математике учащихся, испытывающих трудности в освоении основных образовательных программ общего образования, развитии и социальной адаптации, в том числе детей с ОВ3.

Общая трудоемкость дисциплины «Методика обучения математике детей с особыми образовательными потребностями» составляет 6 зачетных единиц, 216 часов (из них 108 часов (3 зачетных единицы) отводится на изучение раздела «Методика обучения математике учащихся, испытывающих трудности в освоении ос- новных образовательных программ общего образования, развитии и социальной адаптации, в том числе детей с ограниченными возможностями здоровья»). Приведем примерное содержание раздела.

Модуль 1. Психолого-педагогические аспекты и нормативно-документальное обеспечение обучения, воспитания и развития учащихся, испытывающих трудности в освоении основных образовательных программ общего образования, развитии и социальной адаптации.

Характеристика состояния здоровья детского населения на современном этапе развития человеческой цивилизации. Разные подходы к классификации детей, испытывающих трудности в освоении основных образовательных программ общего образования, развитии и социальной адаптации. Неоднородность состава группы детей с ОВ3. Современные тенденции в изменении состава детей с ОВ3.

Психолого-педагогическая диагностика особых образовательных потребностей у детей, испытывающих трудности в освоении основных общеобразовательных программ, развитии и социальной адаптации.

Коррекционно-развивающее и компенсирующее обучение детей с трудностями в освоении основных образовательных программ общего образования, развитии и социальной адаптации: основные понятия и нормативно-документальное обеспечение.

Инклюзивное (интегрированное) образование учащихся с ОВ3: основные понятия, нормативно-документальное обеспечение, проблемы и перспективы внедрения.

Федеральный государственный образовательный стандарт для обучающихся с ограниченными возможностями здоровья (проект). Дифференциация ФГОС для обучающихся с ОВ3 (четыре базовых варианта). Варианты требований стандарта, предусмотренные для каждой категории обучающихся с ОВ3. Адаптированные основные образовательные программы общего образования для обучающихся с ОВ3.

Модуль 2. Общие вопросы методики обучения математике учащихся, испытывающих трудности в освоении основных образовательных программ общего образования, развитии и социальной адаптации.

Цели и принципы обучения математике учащихся, испытывающих трудности в освоении основных образовательных программ общего образования, развитии и социальной адаптации. Специфика усвоения математических знаний, умений и навыков учащимися, испытывающими трудности в освоении основных образовательных программ общего образования, развитии и социальной адаптации.

Содержание математического образования учащихся, испытывающих трудности в освоении основных образовательных программ общего образования, развитии и социальной адаптации. Примерные адаптированные образовательные программы общего образования для обучающихся с ОВ3, учебный план, индивидуальный учебный план, образовательный маршрут, индивидуальный образовательный маршрут. Учебники, учебные пособия, иная учебная литература для учащихся, испытывающих трудности в освоении основных образовательных программ общего образования, развитии и социальной адаптации. Методы и технологии обучения, воспитания и развития. 
Планирование работы учителя математики с учащимися, испытывающими трудности в освоении основных образовательных программ общего образования, развитии и социальной адаптации. Урок как основная форма обучения математике учащихся, испытывающих трудности в освоении основных образовательных программ общего образования, развитии и социальной адаптации. Специфика формирования математических понятий. Методика работы с правилами и алгоритмами. Обучение решению задач. Изучение теорем. Контроль знаний и умений учащихся при обучении математике.

Воспитание и развитие учащихся, испытывающих трудности в освоении основных образовательных программ общего образования, развитии и социальной адаптации, при обучении математике.

Внеурочная коррекционно-развивающая работа по математике с обучающимися с ОВ3. Дистанционная поддержка математического образования детей с OB3.

Модуль 3. Частные вопросы методики обучения математике учащихся, испытывающих трудности в освоении основных образовательных программ общего образования, развитии и социальной адаптации.

Математика как средство коррекции недостатков развития дошкольников и младших школьников с ОВ3.

Обучение на уроках математики учащихся 5-6 классов, испытывающих трудности в освоении основных образовательных программ общего образования, развитии и социальной адаптации.

Избранные вопросы методики обучения алгебре учащихся 7-9 классов, испытывающих трудности в освоении основных образовательных программ общего образования, развитии и социальной адаптации.

Избранные вопросы методики обучения геометрии учащихся 7-9 классов, испытывающих трудности в освоении основных образовательных программ, развитии и социальной адаптации.

При изучении раздела «Методика обучения математике учащихся, испытывающих трудности в освоении основных образовательных программ общего образования, развитии и социальной адаптации, в том числе детей с ограниченными возможностями здоровья» предусмотрено выполнение контрольной работы «Методическая разработка одной из тем школьного курса математики для учащихся, испытывающих трудности в освоении основных общеобразовательных программ, развитии и социальной адаптации». В контрольной работе должны быть (в произвольной последовательности) освещены следующие вопросы.

1. Анализ рабочей программы, учебников и учебных пособий для учащихся, испытывающих трудности в освоении основных образовательных программ общего образования, развитии и социальной адаптации.

2. Пропедевтика изучения темы.

3. Методика введения математических понятий.

4. Работа над алгоритмами, правилами, теоремами.

5. Методика обучения учащихся решению задач.

6. Диагностика результативности изучения темы.

7. Организация изучения темы (тематический план, планы-конспекты уроков) с учетом возрастных (познавательных, гендерных, психосоциальных и других особенностей развития детей с ОВ3). Подготовка дидактических материалов (в том числе карточек для коррекции знаний).
8. Использование при изучении темы средств наглядности, технических средств обучения, современных образовательных технологий (включая информационные), а также цифровых образовательных ресурсов.

9. Воспитание и развитие учащихся при изучении темы.

10. Внеурочная работа.

Одна из наиболее эффективных форм обучения будущих учителей - деловая игра [13-18]. В качестве примера приведем игру «Урок математики для учащихся, испытывающих трудности в освоении основных образовательных программ общего образования, развитии и социальной адаптации».

Оборудование: программы, учебники, учебные пособия.

\section{Предварительные задания}

1. Ознакомиться с материалами по теме урока (программа, учебники, пособия для учителя и учащихся и тп.).

2. Составить список литературы, используемой учителем к данному уроку.

3. Продумать вопросы, которые учащиеся могут задать учителю.

4. Оформить в рабочей тетради возможные записи учителя и учащихся на доске и в тетрадях.

5. Изготовить наглядные пособия к проигрываемому уроку.

6. Один студент, выступающий в роли учителя на уроке, составляет план-конспект урока, подбирает систему упражнений, выполняемых на уроке и предназначенных для домашнего задания.

\section{Содержание занятия}

1. Проведение коррекционно-развивающего урока на тему, избранную «учителем»-студентом, и изучение нового материала «учениками»-остальными студентами (два человека выделяются из группы для проведения анлиза урока)

2. Обсуждение урока в соответствии со схемой его анализа и выполнением предварительных заданий студентами.

3. Выявление коррекционно-развивающих возможностей урока (актуальных и потенциальных). Степень их реализации на практике.

После изучения раздела «Методика обучения математике учащихся, испытывающих трудности в освоении основных образовательных программ общего образования, развитии и социальной адаптации, в том числе детей с ограниченными возможностями здоровья» будущим бакалаврам педагогического образования предлагается выполнить курсовую работу на одну из предложенных ниже тем [19-21].

1. Перспективы внедрения инклюзивного образования учащихся с ограниченными возможностями здоровья в России.

2. Сравнительный анализ методики обучения математике учащихся с ограниченными возможностями здоровья в России и за рубежом.

3. Гендерный подход к обучению математике детей с ограниченными возможностями здоровья.

5. Урок математики для учащихся с ограниченными возможностями здоровья.

6. Основные формы изучения нового математического материала детьми с ограниченными возможностями здоровья. 
7. Закрепление знаний учащимися с ограниченными возможностями здоровья при изучении математики.

9. Повторение, обобщение и систематизация математических знаний учащимися с ограниченными возможностями здоровья.

10. Контроль и коррекция знаний по математике учащихся с ограниченными возможностями здоровья.

11. Инновационные технологии в обучении математике учащихся с ограниченными возможностями здоровья.

12. Региональный опыт обучения математике учащихся с ограниченными возможностями здоровья.

\section{СПИСОК ЛИТЕРАТУРЫ:}

1. Национальная образовательная инициатива «Наша новая школа» // http://минобрнауки.рф /documents/1450.

2. Национальная стратегия действий в интересах детей на 2012-2017 годы // http://base.garant.ru/70183566.

3. Кондаурова И.К., Кулибаба О.М. Профессионально-методическая подготовка учителя математики к обучению детей с особыми образовательными потребностями // Профессиональное образование. Столица. 2008. № 3. C. 32-33.

4. Емельянова Т.В. Теоретические вопросы формирования правовой компетентности будущих педагогов инклюзивного образования // Вестник Гуманитарного института ТГУ. 2014. № 2 (16). С. 15-18.

5. Кондаурова И.К., Гусева М.А. Место дисциплины «Введение в систему математического образования россии» в профессиональном становлении педагогаматематика // Карельский научный журнал. 2014. № 4. C. $62-65$.

6. Синявская А.А. Понятие «готовность к работе в условиях инклюзивного образования» в современных психолого-педагогических исследованиях // Вестник Гуманитарного института ТГУ. 2015. № 2 (18). С. 28-31.

7. Ахметова Д.З. Идеи концепции непрерывного инклюзивного образования // Карельский научный журнал. 2014. № 1. С. 44-46.

8. Яковлева Е.Л. Другие как предпосылка формирования инклюзивного пространства и образования // Балтийский гуманитарный журнал. 2014. № 3. С. 15-18.

9. Бурмистрова О.В. Профессиональная подготовка студентов-логопедов в условиях осуществления инклюзивного образования // Самарский научный вестник. 2014. № 1 (6). С. 37-39.

10. Яковлева Е.Л. Выявляя причины распространения инклюзии и инклюзивного образования (философский аспект проблемы) // Карельский научный журнал. 2014. № 4. C. 26-29.
11. Емельянова Т.В. Компетентностный «портрет» будущего педагога инклюзивного образования // Вестник Гуманитарного института ТГУ. 2014. № 1 (15). C. $13-17$.

12. Яковлева Е.Л. Опыт философского осмысления инклюзивного человека // Карельский научный журнал. 2015. № 4 (13). C. 12-15.

13. Сергушина О.В., Евсеева Ю.А. Значение дидактических игр на уроках в начальной школе // Азимут научных исследований: педагогика и психология. 2014. № 4. С. 56-57.

14. Смирнова Е.В. Использование средств информационных и коммуникационных мультимедиа-технологий в обучении иностранному языку на ранних этапах возрастного развития // Балтийский гуманитарный журнал. 2015. № 2 (11). С. 114-116.

15. Котова С.А. Исследование формирования вычислительных навыков у старших дошкольников с использованием игр на интерактивной доске // Карельский научный журнал. 2014. №4. С. 65-69.

16. Яковлева Е.Л. Многообразные облики игры: попытка философского осмысления // Азимут научных исследований: педагогика и психология. 2014. № 3. C. $87-90$

17. Одарич И.Н. Технология обучения будущих бакалавров по направлению подготовки 270800 строительство по формированию профессиональных компетенций // Балтийский гуманитарный журнал. 2015. № 4 (13). C. $95-101$

18. Ковалева Н.Б. Роль рефлексии в развитии культуры совместного творчества // Азимут научных исследований: педагогика и психология. 2015. № 4 (13). C. $120-123$.

19. Кондаурова И.К. Дисциплина «Методика обучения математике детей с особыми образовательными потребностями» в системе профессиональной подготовки будущих бакалавров педагогического образования // Гуманитарные науки и образование. 2012. № 1. C. $23-25$.

20. Кондаурова И.К., Гусева М.А. Формирование у будущих педагогов-математиков умений и навыков педагога-исследователя в контексте развития профессиональной биографии // Азимут научных исследований: педагогика и психология. 2014. № 4. С. 69-72.

21. Кондаурова И.К., Гусева М.А. Место дисциплины «Введение в систему математического образования России» в профессиональном становлении педагогаматематика // Карельский научный журнал. 2014. № 4. C. $62-64$.

\section{PREPARING FUTURE TEACHERS TO WORK WITH CHILDREN EXPERIENCING DIFFICULTIES IN MASTERING BASIC EDUCATIONAL PROGRAMS OF GENERAL EDUCATION, DEVELOPMENT AND SOCIAL ADAPTATION}

\section{I.K. Kondaurova, candidate of pedagogical sciences, associate professor, head of the Chair of Mathematics and Methods of Teaching Saratov National Research State University, Saratov (Russia)}

\footnotetext{
Abstract. The article describes the author's approach to the design and implementation of professional-methodical training of future math teachers to work with children experiencing difficulties in mastering basic educational programs of general education, development and social adaptation, including children with disabilities, in the context of the requirements of the National educational initiative «Our new school», the National strategy of actions in interests of children for 2012-2017, a number of other normative documents. Objectives of the study, expected outcomes and approximate contents of the section «Methods of teaching mathematics to students with difficulties in mastering basic educational pro- 
grams of general education, development and social adaptation, including children with disabilities» discipline «Methods of teaching mathematics to children with special educational needs». The structure of the content is presented in three modules. The first is the study of psycho-pedagogical aspects and regulatory documents providing training, education and development of students with difficulties in mastering basic educational programs of general education, development and social adaptation. The second module includes general questions of methodology of teaching mathematics to students with difficulties in mastering basic educational programs of general education, development and social adaptation. The third module presents particular questions of methods of teaching mathematics to students with difficulties in mastering basic educational programs of general education, development and social adaptation. In conclusion, the article presents recommendations on organization of educational and research activity of future teachers of mathematics in the context of the methodological material examined.

Keywords: preparation of future teachers; children with difficulties in mastering basic educational programs of general education, development and social adaptation, children with disabilities.

удК 7А(06)

\section{СТРУКТУРА И СОДЕРЖАНИЕ ПРОФЕССИОНАЛЬНОЙ ФИЗИЧЕСКОЙ КУЛЬТУРЫ ЛИЧНОСТИ}

(C) 2016

С.С. Коровин, доктор педагогических наук, профессор кафедры теории и методики спортивных дисциплин, адаптивной физической культуры и медико-биологических основ физического воспитания

Оренбургский государственный педагогический университет, Оренбург (Россия)

Аннотащия. Первостепенным фактором развития общества, производства его культуры является воспроизводство полноценной личности, сочетающей усвоенность социокультурных ценностей и готовность к их преобразованию и трансляции в социальную практику и, прежде всего, в практику профессиональной деятельности, в наибольшей мере «ответственной» за создание материальных, духовных и художественных ценностей культуры социума. При этом столь масштабное (во временном и качественном смыслах) преобразование личности «через культуру» и «для культуры» в связи с профессиональной деятельностью и биосоциальная природа личности в совокупности обуславливают «привлечение» к этому процессу ценностей профессиональной физической культуры (ПФК). Именно с их использованием в наилучшей мере обеспечивается гармоничное развитие биосоциальных начал личности, системы ее двигательных и личностных потребностей и способностей в соответствии со спецификой профессиональной деятельности в отношении формирования специфического и интергированного личностного состояния - профессиональной физической культуры личности (ПФКЛ), оптимальный и характерный для конкретной профессиональной деятельности уровень которой - фактор и предпосылка качества социализации личности, процессов восполнения ценностей культуры; отражение качества высшего и среднего профессионального образования. Компонентами ПФКЛ, основными ее характеристиками и признаками сформированности являются: физический (оптимальное физическое развитие, прикладная двигательная подготовленность (психомоторная сфера), физическая адаптация); когнитивно-интеллектуальный (теоретическая подготовленность в сфере ПФК, состояние профессионально значимых психических процессов); аксиологический (ценностные ориентации в сфере ПФК и системе общесоциальных ценностей); физкультурно-деятельностный (мотивы и потребности, включенность в профилированную физкультурно-спортивную деятельность и инструкторскую деятельность в ней). Приводятся также и основные признаки сформированности каждого из выявленных компонентов ПФКЛ.

Ключевые слова: профессиональная физическая культура как социальное явление; структура профессиональной физической культуры личности, ее компоненты, характеристики, признаки сформированности.

Постановка проблемы в общем виде и ее связь с важными научными и практическими задачами. Всегда и на всех этапах социального развития на первый план выдвигается социально обусловленная потребность производства и воспроизводства человека как полноценной личности, отражающей в себе, во-первых, усвоенность совокупности социокультурных ценностей и готовой, во-вторых, к их преобразованию и трансляции в социум с целью поступательного прогресса, движения; создания, воссоздания и упрочения культуры общества в различных ее (культуры) сферах существования и проявления.

Принимая во внимание, что культура существует в материальной, духовной и художественной сферах [1, $2,3]$ и проявляется прежде в условиях жизни, культуре профессиональной и культуре личности [2], возникает социальная и личностная потребность в воспроизводстве и «самовоспроизводстве» соответствующего требованиям времени и профессиональной деятельности «человеческого фактора» со специфическим «набором» двигательных и личностных потребностей и способностей, «сверхприродных», «надбиологических» свойств и качеств, которые не могут быть приобретены в ходе естественного развития, но вполне достижимы за счет внешнего - образовательного - вмешательства.

Именно за счет адекватных личностных и двигательных свойств, качеств и функций, отражающих не только требования социальной практики вообще, но требования конкретного производства, достигается наиболее полная готовность человека, личности к полноценной и полномасштабной (в рамках компетенций) деятельности по производству материальных, духовных и художественных ценностей общества.

Столь тонкое (по характеру) и масштабное (по времени и объему) преобразование индивида в соответствии с требованиями общесоциальной и профессиональной деятельности безусловно принадлежит системе непрерывного образования, которая на каждом из 